\title{
Análise de conflito e dinâmica de uso da terra no município de Salto do Céu/MT
}

Este trabalho tem o objetivo de avaliar, por meio de geotecnologias, os conflitos e a dinâmica do uso da terra do município de Salto do Céu - MT. Foram utilizadas as imagens do Landsat 5 e Landsat 8 dos anos de 1984, 1993, 2003 e 2013, nas quais foram empregadas as técnicas de recorte, segmentação, classificação supervisionada e pós-classificação. A metodologia constou das etapas: definição dos compartimentos morfopedológicos, gerada pela associação dos mapas de geomorfologia e pedologia; análise da capacidade de uso das terras; e avaliação dos conflitos existentes quanto ao uso atual do solo em relação à referida capacidade de uso. Por fim, foram feitas as quantificações e elaborados os mapas. A Savana Florestada foi suprimida em $12,47 \%$ no período de 20 anos. A maioria das fitofisionomias foram substituídas pela Pecuária, ocorrendo um aumento de $16,90 \%$ dessa classe ao longo do período estudado. A Influência urbana apresentou $159,81 \%$ de crescimento no período analisado, o que pode ser devido o crescimento das atividades agropecuárias regionais, dando origem a comunidades e distritos próximos. Verificou-se que o município tem $58,10 \%$ de suas terras adaptadas para pastagens e reflorestamento, com problemas simples quanto à conservação. As áreas identificadas com baixo conflito de uso da terra representaram $72,28 \%$ da área total do município. Concluiu-se que a vegetação natural fo suprimida para que ocorresse a expansão da Pecuária e da área urbana, demostrando que a alteração da paisagem está condicionada pela economia regional, em que a Pecuária constitui a principal atividade. A análise indicou que o município de Salto do Céu possui terras com alto potencial de uso para Pecuária por apresentarem aptidão para o desenvolvimento da atividade, o que sugere que essas áreas se encontram em relativo equilíbrio entre o suporte ecológico (no que diz respeito principalmente à susceptibilidade à erosão linear) e a exploração socioeconômica. Há necessidade de readequação do uso das terras nas áreas que apresentaram atividades em que ocorre alto conflito, bem como a fiscalização e controle nas mudanças dos usos, para que não ocorram problemas futuros relacionados à erosão.

Palavras-chave: Sistemas de Informação Geográfica; Degradação Ambiental; Cobertura do Solo.

\section{Analysis of conflicts and land use dynamics in the municipality Salto do Céu - Mato Grosso state}

\begin{abstract}
The objective of this paper was to evaluate, using geo-technologies, the conflicts and dynamics of land use in the municipality Salto do Céu - Mato Grosso State (Brazil). LANDSAT 5 and 8 images, from 1984, 1993, 2003 and 2013 were used for clipping, segmentation, supervised classification and post-classification. The methodology consisted of the following steps: definition maps; analysis of land use capacity and evaluation of existing conflicts regarding the current land use related to its capacity of use. Finally, quantifications were made concluding with the elaboration of maps. Forested Savanna was suppressed by $12.47 \%$ in the period of 20 years. Most phyto-physiognomies were replaced by Livestock, which increased by $16.90 \%$ during the period studied. The urban area grew $159.81 \%$ in this timeframe, due to the increase of agriculture and livestock. This municipality adapted $58.10 \%$ of its land for pasture and reforestation, with simple problems regarding conservation. Those areas identified as of low land use conflicts accounted for $72.28 \%$ of the municipal area. The analysis performed, indicates that the municipality has lands with high potential for livestock use, because these areas are adequate for the development of this activity. This suggests that these areas are in a relative balance between the ecological support (regarding mainly its susceptibility to linear erosion) and the socio-economic exploitation. It was concluded that the natural vegetation was suppressed for the expansion of Livestock and the urban area, showing that the landscape alteration was conditioned by the regional economy. There is a need for the readjustment of land use in those areas with strong conflicts, as well as inspection and control of land use changes, in order to avoid future soil erosion problems.
\end{abstract}

Keywords: Geographic Information Systems; Environmental Degradation; Use and Coverage.

\section{Topic: Química Agrícola e Ambiental}

Reviewed anonymously in the process of blind peer.

Camila Calazans da Silva Luz

Universidade do Estado de Mato Grosso, Brasil

http://lattes.cnpq.br/4995350248582972

camila agronomia@hotmail.com

\section{Ronaldo José Neves}

Universidade do Estado de Mato Grosso, Brasil

http://lattes.cnpq.br/5794831112557727

hellentortorelli@gmail.com

Sandra Mara Alves da Silva Neves

Universidade do Estado de Mato Grosso, Brasil

http://lattes.cnpq.br/6430066425008976

ssneves@unemat.br
Received: 19/04/2016

Approved: 21/05/2016

\author{
Larissa Espinosa de Freitas \\ Universidade do Estado de Mato Grosso, Brasil \\ http://lattes.cnpq.br/8576912622079606 \\ larissa-efreitas@hotmail.com \\ Miriam Raquel da Silva Miranda \\ Universidade do Estado de Mato Grosso, Brasil \\ http://lattes.cnpq.br/0076499327484052 \\ miriamraquel18@gmail.com \\ Maria Cândida Moitinho Nunes \\ Universidade Federal de Pelotas, Brasil \\ http://lattes.cnpq.br/3197317934141386 \\ nunes.candida@gmail.com
}

\section{Referencing this:}

LUZ, C. C. S.; NEVES, R. J.; NEVES, S. M. A. S.; FREITAS, L. E.; MIRANDA, M. R. S.; NUNES, M. C. M.. Análise de conflito e dinâmica de uso da terra no município de Salto do Céu/MT. Revista Ibero-Americana de Ciências Ambientais, v.8, n.1, p.194-207, 2017. DOI:

http://doi.org/10.6008/SPC2179-6858.2017.001.0017 


\section{INTRODUÇÃO}

O município de Salto do Céu está localizado na região sudoeste do estado de Mato Grosso e na Bacia do Alto Paraguai (BAP). Sua economia é baseada na agropecuária, com inúmeros assentamentos e pequenos produtores rurais. Sendo que a implantação da agropecuária e a ocupação desordenada regional tem intensificado o desmatamento de grande parte da vegetação natural, exercendo pressões sobre os recursos naturais. Esta situação tem levantando questionamentos no que diz respeito ao manejo do solo e conservação do ambiente (COSTA et al., 2013).

O estudo do uso e ocupação da terra em escala municipal consiste em identificar a forma de utilização das áreas de interesse, permitindo uma caracterização e representação espacial das interações antrópicas com o meio ambiente (SANTOS \& PETRONZIO, 2011). Desta maneira, análises temporais de uso e ocupação da terra são importantes ferramentas para a verificação da situação ambiental local, para compreensão da intensidade das mudanças e o período em que elas ocorreram, como também, para fomentar análises das pressões socioeconômicas atuais, contribuindo para melhor gerenciamento de recursos naturais e planejamento urbano (SEABRA \& CRUZ, 2013; SCHIAVO et al., 2015). Nesse contexto, as técnicas informatizadas de análise espacial são apontadas por muitos estudiosos como de fundamental relevância para compor ações e estratégias de preservação ambiental através da compreensão do dinamismo do uso e da ocupação das terras (SCHNEIDER \& TARTARUGA, 2004; MIRANDA et al., 2014; CARVALHO et al., 2003).

O emprego das Geotecnologias possibilita verificar se o uso da terra está sendo realizado de forma adequada, sendo esse o passo inicial no sentido da conservação dos elementos naturais da paisagem e na busca de uma agricultura sustentável. Além disso, é primordial a utilização de metodologias que determinem capacidade de sustentação do solo e sua produtividade econômica, de tal forma que os recursos naturais sejam colocados à disposição do homem para o seu melhor uso e benefício, ao mesmo tempo em que são preservados para gerações futuras (BERTOLINI \& BELLINAZZI JR, 1994).

A análise dos conflitos de uso da terra possibilita a obtenção de informações importantes para a conservação de forma eficiente e relativamente rápida, através da comparação dos tipos de uso com as classes de capacidade de uso e suscetibilidade a erosão.

Os resultados obtidos, a partir da utilização desses procedimentos técnicos, podem auxiliar no desenvolvimento das atividades produtivas no espaço rural, na elaboração de planejamento econômico e ambiental municipal e na proposição de medidas que reduzam os efeitos negativos da produção animal no ambiente. Face ao exposto, o objetivo deste estudo é analisar, por meio de geotecnologias, os conflitos e a dinâmica do uso da terra no município de Salto do Céu - MT.

\section{METODOLOGIA}

\section{Área de Estudo}

O município de Salto do Céu, criado pela Lei no 4.152/1979 (MATO GROSSO, 1979), está situado na região sudoeste de planejamento do estado de Mato Grosso (MATO GROSSO, 2012), com extensão territorial 
de $1.752,34 \mathrm{~km}^{2}$ (Figura 01), 44,1\% da população residente na zona rural cuja base da economia é a agropecuária (IBGE, 2015). A área territorial municipal encontra-se distribuída em dois biomas, sendo 13,26\% no Cerrado e $86,74 \%$ no Amazônia.

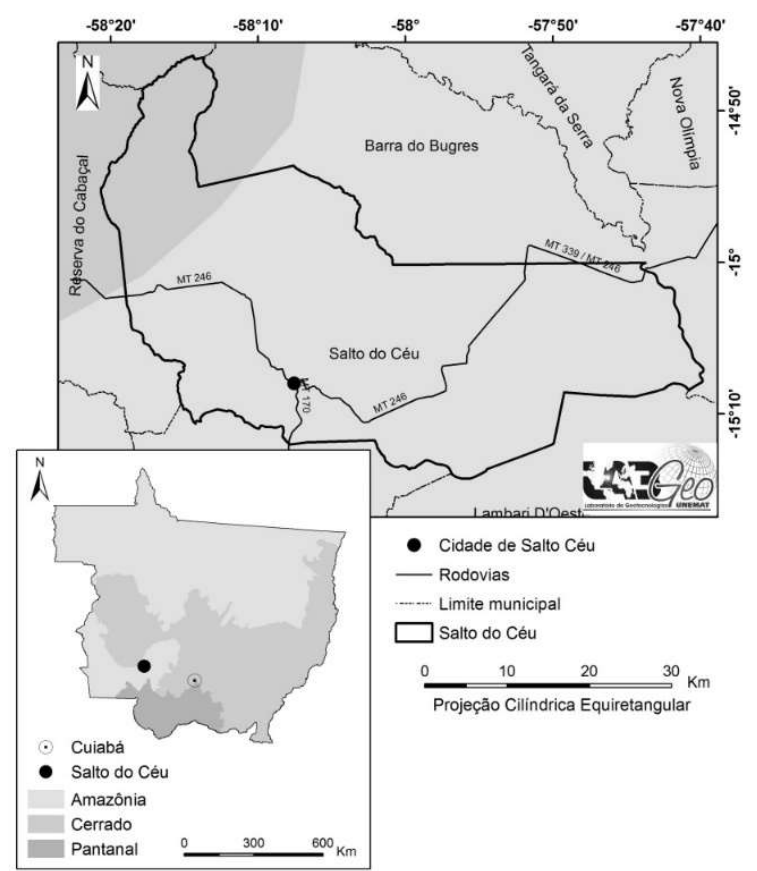

Figura 01: Município de Salto do Céu/MT nos contextos dos biomas em Mato Grosso e municipal.

O clima municipal é o Tropical, com temperatura anual variando de $24,1 \mathrm{C}$ a 26 으 e precipitação anual de 1601 a 1800mm (TARIFA, 2011). O solo predominante é do tipo Argissolo Vermelho distrófico (MATO GROSSO, 2007).

\section{Procedimentos Metodológicos}

Obteve-se as bases cartográficas dos mapeamentos de pedologia e geomorfologia, na escala de 1:250.000, junto a Secretaria de Estado de Planejamento e Coordenação Geral - SEPLAN (MATO GROSSO, 2016). Estes foram posteriormente compilados, compatibilizados e organizados em um Banco de Dados Geográficos no ArcGIS, versão 10.5 (ESRI, 2017).

Foram adquiridas imagens do satélite Landsat 5 e 8, órbita/ponto 228-71, dos anos de 1984, 1993, 2003 e 2013, do período seco. O georreferenciamento das imagens Landsat 5 foi realizado no Sistema de Processamento de Informações Georreferenciadas - SPRING do Instituto Nacional de Pesquisas Espaciais INPE (CÂMARA et al., 1996), utilizando o modo tela-a-tela, com obtenção de 14 pontos de controle, considerando a distribuição sobre toda a superfície da imagem, utilizando como referência a imagem do satélite Landsat 8 de 2013. Na sequência para gerar o mapa de uso da terra e cobertura vegetal realizou-se recorte, segmentação, classificação supervisionada e pós-classificação. Para o recorte foi usada a base cartográfica digital do município como máscara (IBGE, 2016).

Na segmentação foi utilizado o método de crescimento de regiões, onde definiu-se os valores de similaridade 10 e área 8. Na classificação supervisionada foram estabelecidas nove classes, definidas a partir 
de pesquisa bibliográfica nos relatórios do Projeto de Conservação e Utilização Sustentável da Diversidade Biológica Brasileira - PROBIO I (BRASIL, 2007) e no Manual técnico para vegetação e uso da terra (IBGE, 2012). O classificador utilizado nessa etapa foi o Bhattacharya, com limiar de aceitação de 99,99\%.

A classificação gerada foi exporta no formato shapefile e no ArcGis 10.5 (ESRI, 2017) procedeu-se a pós-classificação, cujas classes foram validadas através dos dados obtidos no campo. Realizada a correção dos equívocos derivados da etapa de classificação foram elaboradas as quantificações e layouts dos mapas.

Foi realizada a compartimentação morfopedológica da área, por meio de intersecção dos mapas geomorfológico e pedológico, através da utilização da ferramenta intersect, disponível no software ArcGis, conforme Nunes et al. (2013).

A capacidade de uso está relacionada ao grau de risco de degradação dos solos e a indicação do seu melhor uso agrícola. Este sistema proposto por Lepsch (1991) estabeleceu categorias com base nos tipos e intensidade de uso, sistematizadas em grupos com suas classes, conforme apresentado a seguir:

Grupo A - Terras aptas a cultivos intensivos anuais, culturas perenes, pastagens e reflorestamentos, compreendendo as seguintes classes:

Classe I - correspondem às terras cultiváveis sem problemas de erosão. Terrenos sem problemas especiais de conservação, podendo ser utilizados com qualquer tipo de cultura;

Classe II - são as terras cultiváveis com problemas simples de erosão (ravinas e sulcos), podendo ser utilizados com qualquer tipo de cultura, porém exigindo práticas simples de controle de erosão;

Classe III - são as terras cultiváveis apenas ocasionalmente com problemas de erosão e conservação; mais indicados a pastagens e culturas perenes e, eventualmente, a culturas anuais, porém exigindo práticas intensivas mecanizadas de controle de erosão; e

Classe IV - são as terras cultiváveis apenas ocasionalmente, onde os terrenos apresentam problemas complexos de conservação; indicados para pastagens e culturas perenes.

Grupo B - Terras impróprias para cultivos, mas aptas para pastagens, compreendendo as seguintes classes:

Classe $V$ - Sem problemas de erosão e conservação, mas exigindo técnicas especiais de cultivo, por se constituírem de solos mal drenados;

Classe VI - Problemas de conservação, parcialmente favoráveis à ocupação por pastagens, sendo mais apropriados para reflorestamento; e

Classe VII - Problemas complexos de conservação, indicados para preservação ou reflorestamento.

Grupo C - Terras indicadas somente para a preservação, compreendendo a classe:

Classe VIII - corresponde às áreas de proteção ambiental, onde os terrenos apresentam problemas complexos de conservação; indicados para preservação.

Salomão (1999) relacionou as classes de suscetibilidade à erosão linear com as classes de capacidade de uso das terras definidas por Lepsch (1991), conforme apresentado na tabela 1, sendo esta nesta pesquisa operacionalizada no ArcGIS para viabilizar a elaboração do mapa de capacidade de uso do município.

Tabela 1: Correspondência das classes de suscetibilidade à erosão linear com as de capacidade de uso das terras.

\begin{tabular}{ll}
\hline \multicolumn{1}{c}{ Suscetibilidade à erosão (Salomão, 1999) } & Capacidade de uso das terras (Lepsch, 1991) \\
\hline Classe I - Extremamente suscetível & Classes VII e VIII \\
Classe II - Muito suscetível & Classe VI \\
Classe III - Moderadamente suscetível & Classe IV
\end{tabular}


Classe IV - Pouco suscetível

Classe V - Pouco a não suscetível
Classe III

Classe I, II e V

Para análise dos conflitos de uso da terra foram associadas as informações de suscetibilidade à erosão/capacidade de uso das terras e a cobertura vegetal e uso da terra de 2013. As classes do mapa de conflitos foram definidas em: nulo, baixo, médio e alto conflito, segundo a metodologia proposta por Hermuche et al. (2009). Os mapas gerados foram exportados no formato shapefile para que no ArcGIS fossem elaboradas as quantificações das classes e os layouts, que se encontram apresentados no item resultados e discussão.

\section{RESULTADOS E DISCUSSÃO}

\section{Dinâmica da Cobertura Vegetal e Uso da Terra}

Foram mapeadas nove classes temáticas: Floresta Aluvial, Floresta Submontana, Savana Florestada, Savana Arborizada com Presença de Savana Florestada, Savana Parque com Presença de Savana Arborizada, Pecuária, Influência urbana, Silvicultura e Corpos d'água, cujos totais de área constam na tabela 1 e são espacializados na Figura 2.

Tabela 2: Cobertura vegetal e uso da terra no município de Salto do Céu - MT, no período de estudo.

\begin{tabular}{lrrrr}
\hline & \multicolumn{1}{c}{ Formação } & \multicolumn{3}{c}{ Área (ha) } \\
\cline { 2 - 5 } & \multicolumn{1}{c}{1984} & \multicolumn{1}{c}{2003} & \multicolumn{1}{c}{2013} \\
\hline Floresta Aluvial & $12.390,85$ & $12.055,49$ & $11.879,71$ & $12.103,06$ \\
Floresta Submontana & $1.483,67$ & $1.472,84$ & $1.496,45$ & $1.433,37$ \\
Savana Florestada & $28.236,62$ & $18.273,97$ & $12.327,28$ & $11.537,18$ \\
Savana Arborizada com Presença de Savana Florestada & $7.606,50$ & $5.163,18$ & $4.038,57$ & $3.738,78$ \\
Savana Parque com Presença de Savana Arborizada & $29.659,48$ & $28.565,66$ & $24.665,16$ & $22.388,68$ \\
Pecuária & $95.275,74$ & $109.085,35$ & $120.177,01$ & $126.051,48$ \\
Influência urbana & 51,58 & 118,37 & 121,14 & 134,00 \\
Silvicultura & - & - & - & 310,89 \\
Corpos d'água & 444,64 & 414,19 & 443,76 & 446,63 \\
\hline Totais & $175.149,07$ & $175.149,07$ & $175.149,07$ & $175.149,07$ \\
\hline
\end{tabular}

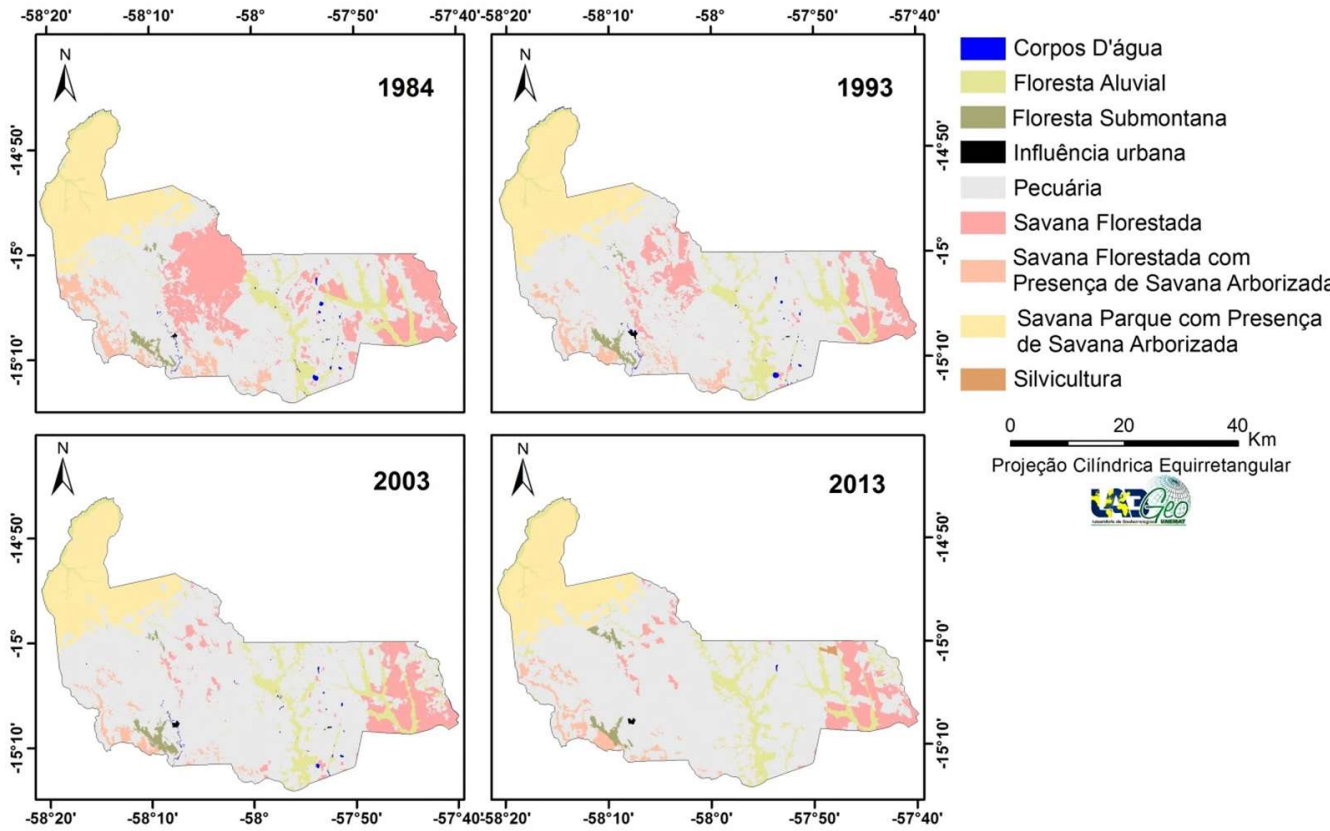

Figura 02: Cobertura vegetal e uso da terra no município de Salto do Céu - MT, nos aos de 1984, 1993, 2003 e 2013. 
Floresta Aluvial é como se denomina a formação ribeirinha ou floresta ciliar que ocorre ao longo dos cursos de água, ocupando os terrenos antigos das planícies quaternárias, que podem estar sujeitas às inundações permanentes ou periodicamente, apresentando vegetação higrófita (IBGE, 2012). De acordo com Salo \& Räsänem (1990), a comunidade biótica dessas áreas está em constante instabilidade e reorganização, pois seu estabelecimento, crescimento e reprodução são influenciados pelos níveis da água. Essa classe foi suprimida pela implantação da pecuária, ocupando apenas 6,65\% da área municipal (Figura 3).

A Floresta Submontana de Salto do Céu ocorre nas encostas de serras, cujas rochas são formadas por calcários (MIRANDA et al., 2014; BRASIL, 2012;) (Figura 4), tendo a classe no período de estudo decrescido 3,39\%. Esta situação está em desacordo com Código Florestal (BRASIL, 2012), que prevê como Área de Preservação Permanente - APP as encostas ou partes destas com declividade superior a $45^{\circ}$, equivalente a $100 \%$ (cem por cento) na linha de maior declive.

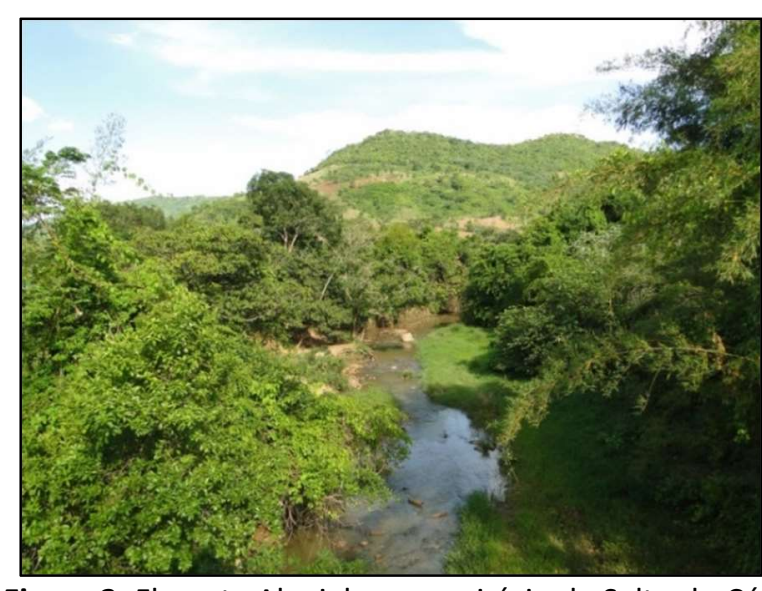

Figura 3: Floresta Aluvial, no município de Salto do Céu - MT. Fonte: LabGeo Unemat (2014).

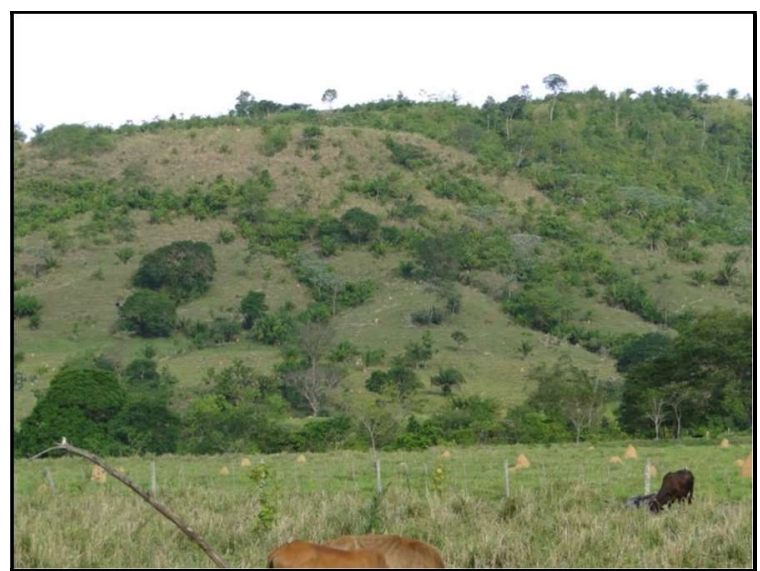

Figura 4: Floresta Submontana no município de Salto do Céu - MT. Fonte: LabGeo Unemat (2014).

A Savana Florestada foi a segunda classe que ocupou maior extensão territorial no município (Tabela 1), entretanto sua redução foi de 59,14\% (Figura 5). Essas áreas denominadas como Cerradão tiveram sua vegetação natural substituída pela Pecuária. Fato que pode ser explicado pelo predomínio de Latossolos e Argissolos Vermelho Distrófico que são passíveis de utilização com culturas anuais, perenes, pastagens e reflorestamento (EMBRAPA, 2006). Monnigel et al. (2009) afirmaram que o uso dessas classes é recomendado para agricultura, devido sua drenagem e favorecimento a mecanização, apesar da baixa fertilidade natural, que pode ser corrigida pela adição de fertilizantes químicos, calcários e adubação verde, aumentando os teores de nutrientes. Segundo Salomão (1999) esses solos apresentam baixa e média erodibilidade, respectivamente.

A classe Savana Arborizada com Presença de Savana Florestada foi a segunda classe em que ocorreu maior supressão ao longo de 29 anos, restando 50,85\% na área do município em 2013 (Figura 6). Essa classe foi substituída pela Pecuária devido a presença de Argissolos que geralmente apresentam boas condições físicas e boa fertilidade natural (EMBRAPA, 2006). Duarte e Theodoro (2002), expuseram que até o ano 2000 mais da metade da área total de Cerrado foi modificada pela atividade agropecuária. 


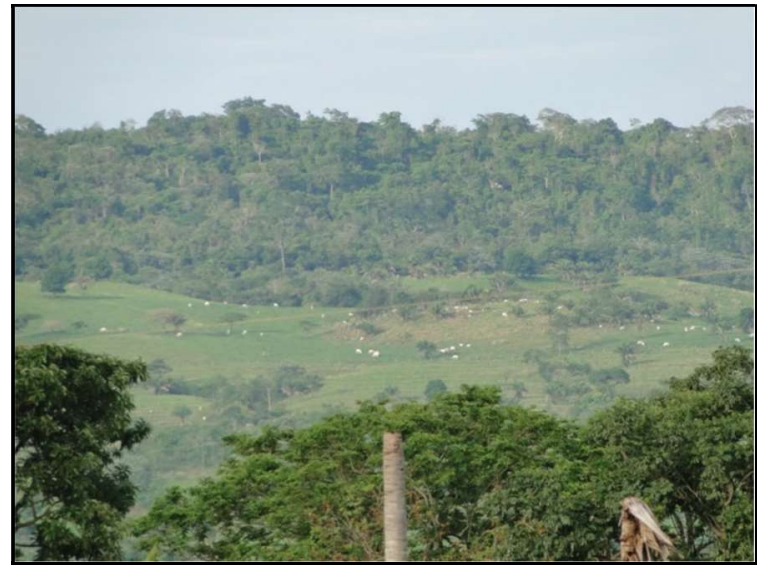

Figura 5: Savana Florestada no município de Salto do Céu MT. Fonte: LabGeo Unemat (2014).

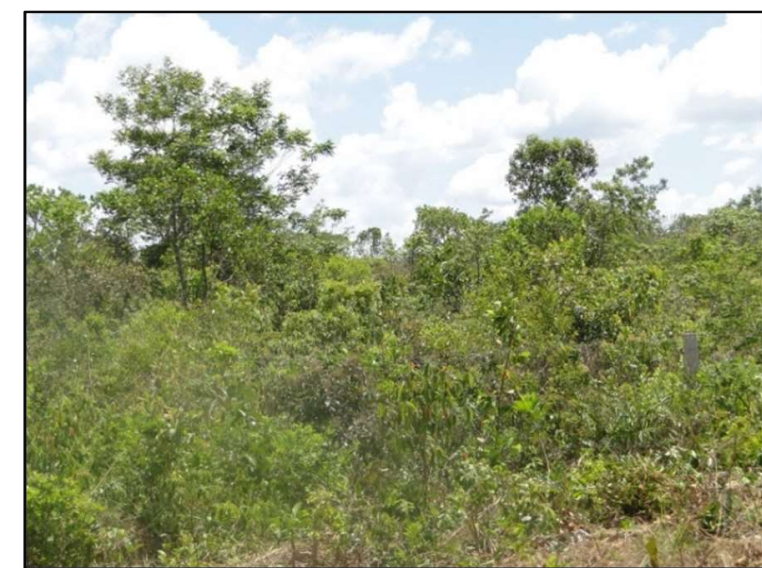

Figura 6: Savana Arborizada com presença de Savana Florestada no município de Salto do Céu - MT. Fonte: LabGeo Unema.t

(2014).

A Savana Parque com Presença de Savana Arborizada (Figura 7) é caracterizada por apresentar uma fisionomia nanofanerofítica rala e outra hemicriptofítica graminóide contínua (BRASIL, 2012). Essa fisionomia foi a terceira classe com maior supressão, apresentando redução de 24,51\% entre 1984 e 2013, cedendo área para a Pecuária. Estudos realizados por Myers et al., (2000) mostraram que essa formação vegetal vem sendo substituída rapidamente por monoculturas, assim como pastagens, transformando o Cerrado em um dos ecossistemas mais ameaçados do mundo. Resultado semelhante foi encontrado por Pessoa et al. (2013) que ao estudar o uso da terra na Interbacia do Rio Paraguai Médio-MT observaram que a vegetação nativa, constituída por esse tipo de formação, estava presente em toda a bacia e sofreu redução de $22,89 \%$ da área com a ocupação por pastagem no período de 20 anos.

Houve aumento de $32,30 \%$ da atividade Pecuária ao longo do período estudado, ocupando 69,21\% do município (Figura 8). O posto de resfriamento de leite da Coopnoroeste contribuiu na expansão da Pecuária leiteira, que constitui a base da economia municipal (MATO GROSSO, 2013). Para Spörl (2001), as áreas de pastagem proporcionam um grau médio de proteção aos solos, pois as gramíneas, com sua densidade de hastes e sistema radicular, e ainda, pela sua capacidade de diminuir a intensidade das enxurradas são bem adaptadas ao controle da erosão. Em contrapartida, a implantação da pecuária pode provocar a morte da microfauna na camada superficial do solo, caso esse seja arado, alterações dos fatores microclimáticos, como temperatura, balanço hídrico e incidência de ventos (ABDON, 2004).

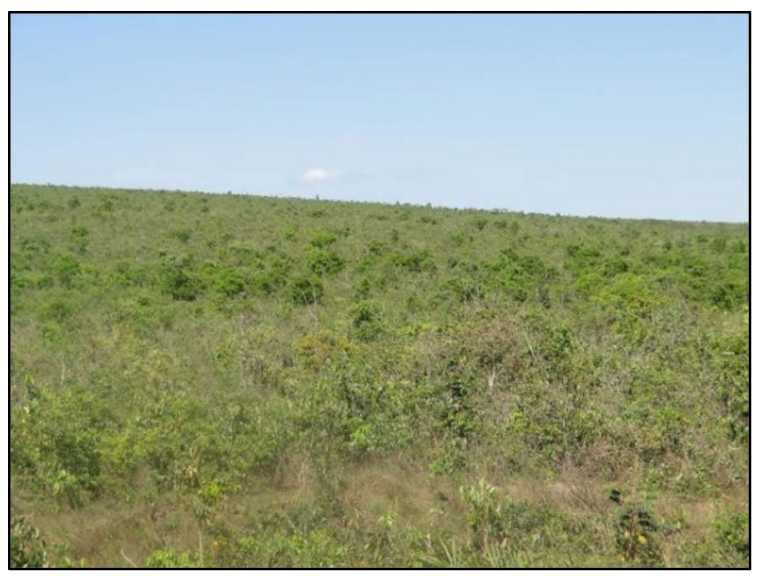

Figura 7: Savana Parque com presença de Savana Arborizada no município de Salto do Céu - MT. Fonte: LabGeo Unemat (2014).

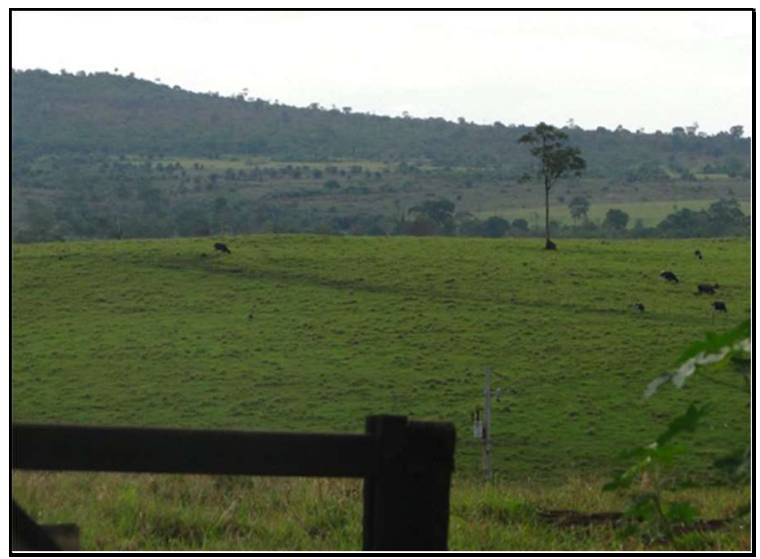

Figura 8: Áreas de pastagem no município de Salto do Céu - MT. Fonte: LabGeo Unemat (2014). 
A Influência urbana apresentou crescimento de 159,81\% no período analisado (Figura 9), influenciado possivelmente pela atividade agropecuárias regional, dado origem aos núcleos urbanos de Cristinópolis, Vila Progresso, Rio Negro, Rio Branquinho, Lua Nova, Jataí, Curupaiti, Tucandira, Santa Rosa, Rio Vermelho, Santa Virgínia, Fortuna, Alto Pito e Lucélia.

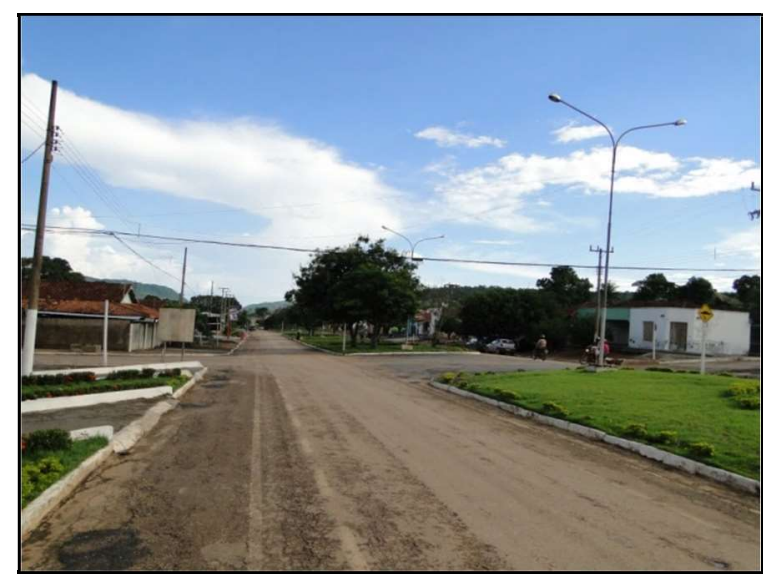

Figura 9: Área urbana no município de Salto do Céu MT. Fonte: LabGeo Unemat (2014).

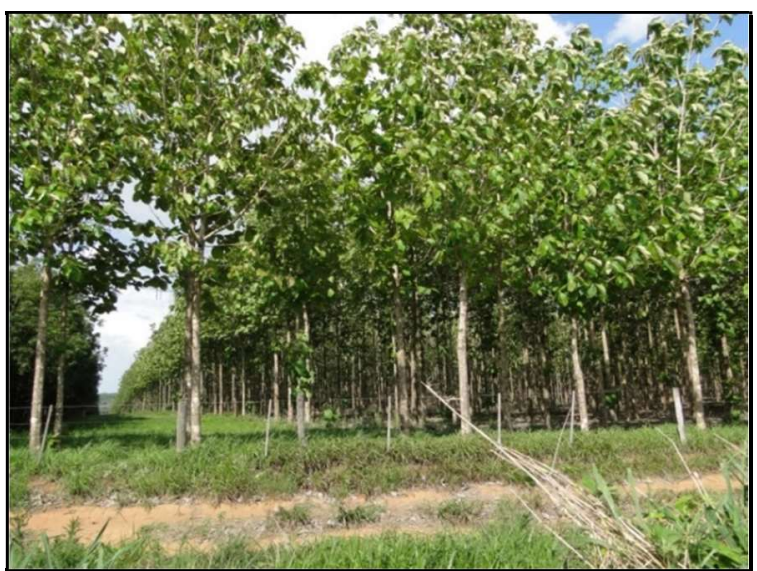

Figura 10: Silvicultura no município de Salto do Céu MT. Fonte: LabGeo Unemat (2014).

A Silvicultura foi mapeada em 2013 , considerando que alguns fatores levaram a sua implantação na região de acordo com Sabogal et al., (2006) foram: auto abastecimento, reposição florestal obrigatória, necessidade de fazer investimentos futuros e o reflorestamento da propriedade em casos dos produtores familiares (Figura 10). Nesse mesmo período foi implantada a Emater, auxiliando na divulgação de técnicas de manejo.

Os percentuais de alteração registrados na classe Corpos d'água do município foram baixos, visto que essa classe tem grande importância para atividades produtivas (Figurar 11) e no abastecimento urbano (Figura 12), assim como sua conservação é favorecida pela legislação (BRASIL, 2012). De acordo Bacha (2001), com o crescimento urbano, ao lado da expansão da agricultura e da agroindústria regional, precisam considerar o volume e a qualidade dos recursos hídricos disponíveis sob pena de comprometimento do próprio desenvolvimento regional.

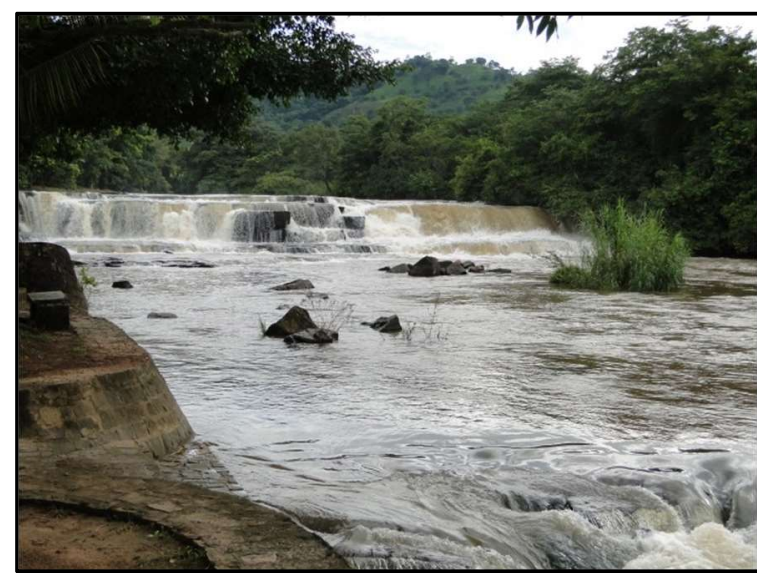

Figura 11: Cachoeira Salto do Céu, ponto turístico no município de Salto do Céu - MT. Fonte: LabGeo Unemat (2014).

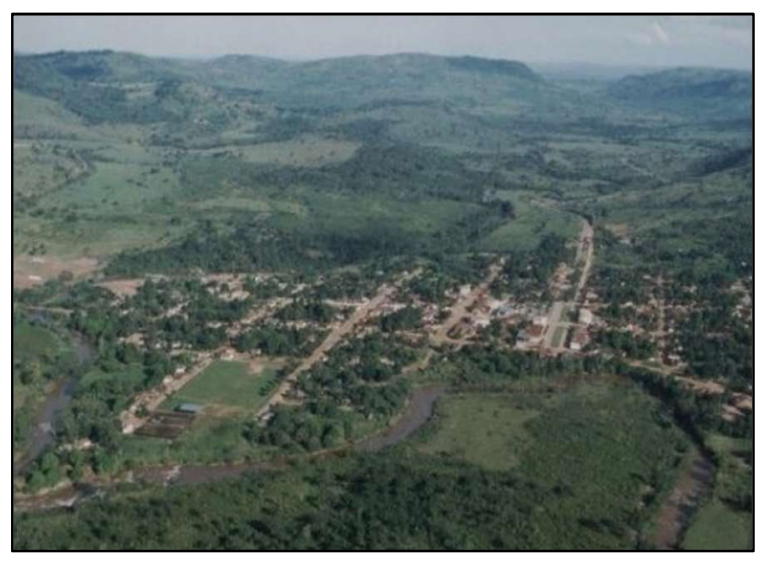

Figura 12: Rio Branco cuja água é utilizada no abastecimento urbano de Salto do Céu - MT. Fonte: Prefeitura Municipal (2011). 


\section{Capacidade de Uso da Terra}

Para melhor compreensão da distribuição da capacidade de uso e de conflitos de uso da terra do município de Salto do Céu foi realizada uma análise associativa dos condicionantes físicos: pedologia e geomorfologia, o que possibilitou a identificação de 11 compartimentos (Figura 13).

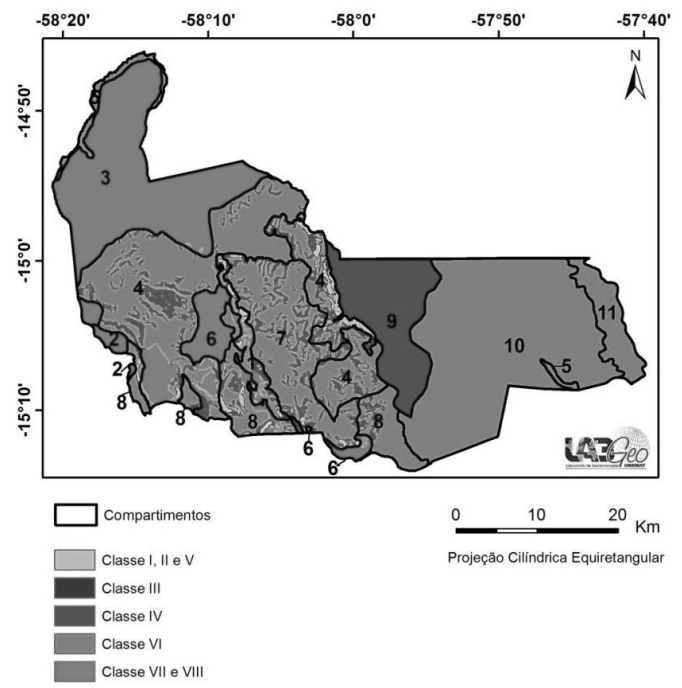

Figura 13: Capacidade de uso da terra do município de Salto do Céu - MT.

No município aproximadamente $58,10 \%$ de suas terras são adaptadas para pastagens e/ou reflorestamento, com problemas quanto à conservação (Classe VI). Nessas áreas predominam os Argissolos, sendo sua maior parte localizada em relevo suave à forte ondulado. De acordo com Antunes et al. (1969) o relevo é outro fator que influencia fortemente as perdas de solo por erosão hídrica, pois, à medida que aumenta o declive, aumenta a capacidade de transporte das partículas de solo pela enxurrada, assim como a própria capacidade desta de desagregar solo. Além de reduzir a capacidade produtiva dos solos para as culturas, como também, pode causar sérios danos ambientais, como assoreamento e poluição das fontes de água. Os solos predominantes nessas áreas apresentam limitações relacionadas a baixa fertilidade, acidez, teores elevados de alumínio e quando são associados a terrenos ondulados a fortemente ondulados, estão propensos aos processos erosivos (EMBRAPA, 2006; FREITAS et al., 2015).

As terras das classes VII e VIII ocupam 22,52\% da área municipal, sendo essas impróprias para culturas e pastagens, mas podem servir como abrigo e proteção da fauna e flora silvestre e, em alguns casos, para reflorestamento, pois apresentam problemas complexos de conservação. Segundo Nunes et al. (2013) essas áreas são consideradas extremamente suscetíveis a erosão, por apresentarem solos frágeis, como os Neossolos, que segundo Zuo et al. (2008) são considerados frágeis, e seu uso agrícola deveria ser evitado, pois quando ocupado de forma desordenada pode ocasionar em áreas suscetíveis à erosão, severos processos de degradação dos solos. Dessa forma, a adoção de técnicas conservacionistas nessas áreas é primordial para evitar os processos erosivos e a degradação ambiental (FARINASSO et al., 2006).

Da área do município 19,38\% são de terras aptas para uso com lavouras (Classes I, II, III, IV e V), devido principalmente a boa fertilidade e a baixa erodibilidade dos solos, relevo plano e clima favorável. 
Desse total, 18,26\% são terras sem problemas de erosão e conservação, porém exigem técnicas especiais de cultivo, por se tratarem de solos mal drenados. Recomenda-se, a divisão da área de culturas anuais em duas partes, destinando uma para pousio. Visto que, segundo Almeida et al. (2008), dentro das diretrizes do manejo conservacionista com culturas anuais é indispensável à implantação de rotação de culturas, buscando um manejo sustável dessas áreas.

\section{Conflitos de Uso da Terra}

Há diversas áreas de conflitos no município de Salto do Céu (Tabela 3), contudo em 72,38\% de extensão territorial constatou-se compatibilidade entre o uso atual da terra e o indicado como adequado na capacidade de uso, que no caso foi a pastagem, provocando um baixo conflito de uso da terra. Segundo Rampim et al. (2012), a utilização correta da terra não depende somente da escolha da atividade a ser implantada seguindo a capacidade do solo indicada, mas também da qualidade de manejo empregado na atividade. Paulino \& Teixeira (2009), corroboram expondo que o manejo correto incluiu: período de descanso e de ocupação tecnicamente recomendados de acordo com a espécie forrageira e categoria animal, taxa de lotação adequada, uso racional de fertilizantes, altura de entrada e saída no piquete.

Tabela 3: Caracterização dos compartimentos morfopedológicos e classificação dos conflitos de uso da terra no município do Salto do Céu - MT.

\begin{tabular}{|c|c|c|c|c|c|}
\hline Compartimento & Relevo & Área (ha) & Cobertura vegetal e uso da terra & Cap. ${ }^{1}$ & Con. $^{2}$ \\
\hline $\begin{array}{l}\text { 1. Sistema de Dissecação em Colinas e } \\
\text { Morros + Cambissolo Háplico. }\end{array}$ & Ondulado & $3.474,35$ & Pecuária e Vegetação Secundária & $\begin{array}{l}\text { VI, III, } \\
\text { VII e VIII }\end{array}$ & Baixo \\
\hline $\begin{array}{l}\text { 2. Sistema de Dissecação em Colinas e } \\
\text { Morros + Neossolo Regolítico Distrófico }\end{array}$ & Plano & 941,37 & Pecuária & VII e VIII & Médio \\
\hline $\begin{array}{l}\text { 3. Sistema regional de Aplanamento } 2 \\
+ \text { Neossolo Quartzarênico }\end{array}$ & Plano & $29.060,98$ & $\begin{array}{l}\text { Floresta Estacional Semi-decidual Submontana, Savana Arborizada com } \\
\text { floresta de Galeria, Savana Florestada, Pecuária e Vegetação Secundária }\end{array}$ & VII e VIII & Médio \\
\hline $\begin{array}{l}\text { 4. Sistema regional de Aplanamento } 2 \\
\text { + Argissolo Vermelho Distrófico }\end{array}$ & $\begin{array}{l}\text { Suave } \\
\text { Ondulado }\end{array}$ & $43.612,94$ & $\begin{array}{l}\text { Floresta Estacional Semi-decidual Submontana, Savana Arborizada com } \\
\text { Floresta de Galeria, Savana Florestada, Pecuária e Vegetação Secundária }\end{array}$ & $\begin{array}{l}\text { II, III, IV } \\
\text { e VI }\end{array}$ & Baixo \\
\hline $\begin{array}{l}\text { 5. Sistema de Planície Fluvial + } \\
\text { Argissolo Vermelho Distrófico }\end{array}$ & Plano & $2.136,958$ & $\begin{array}{c}\text { Área de Tensão Ecológica com contato entre Savana(S) e Floresta Estacional } \\
\text { (C ou F) e Savana Arborizada com Floresta de Galeria. }\end{array}$ & VI & Nulo \\
\hline $\begin{array}{l}\text { 6. Sistema regional de Aplanamento } 2 \\
+ \text { Nitossolo Vermelho Eutrófico }\end{array}$ & $\begin{array}{l}\text { Suave } \\
\text { Ondulado }\end{array}$ & $4.638,314$ & Pecuária e Vegetação Secundária & $\begin{array}{l}\text { IV, VII e } \\
\text { VIII }\end{array}$ & Alto \\
\hline $\begin{array}{l}\text { 7. Sistema de Dissecação em Colinas e } \\
\text { Morros + Argissolo Amarelo Distrófico }\end{array}$ & $\begin{array}{l}\text { Suave } \\
\text { Ondulado }\end{array}$ & $18.228,56$ & Floresta Estacional Decidual Submontana, Pecuária e Vegetação Secundária & IV e VI & Baixo \\
\hline $\begin{array}{l}\text { 8. Sistema de Dissecação em Colinas e } \\
\text { Morros + Argissolo Vermelho Eutrófico }\end{array}$ & $\begin{array}{c}\text { Forte } \\
\text { Ondulado }\end{array}$ & $11.584,88$ & $\begin{array}{c}\text { Área de Tensão Ecológica com contato entre Savana (S) e Floresta Estacional } \\
\text { (C ou F) e Savana Arborizada com Floresta de Galeria, Savana Florestada, } \\
\text { Pecuária e Vegetação Secundária }\end{array}$ & $\begin{array}{l}\text { III, IV e } \\
\text { VI }\end{array}$ & Médio \\
\hline $\begin{array}{l}\text { 9. Sistema de Dissecação em Colinas e } \\
\text { Morros + Latossolo Vermelho } \\
\text { Distrófico }\end{array}$ & Plano & $14.455,95$ & $\begin{array}{l}\text { Área de Tensão Ecológica com contato entre Savana (S) e Floresta Estacional } \\
\text { (C ou F) e Savana Arborizada com Floresta de Galeria e Pecuária }\end{array}$ & IV & Baixo \\
\hline $\begin{array}{l}\text { 10. Sistema de Dissecação + Argissolo } \\
\text { Vermelho Distrófico }\end{array}$ & Plano & $41.908,17$ & $\begin{array}{l}\text { Área de Tensão Ecológica com contato entre Savana (S) e Floresta Estacional } \\
\text { (C ou F) e Savana Arborizada com Floresta de Galeria, Água e Pecuária }\end{array}$ & $\mathrm{VI}$ & Baixo \\
\hline $\begin{array}{l}\text { 11. Sistema regional de Aplanamento } 3 \\
+ \text { Argissolo Vermelho Distrófico }\end{array}$ & Plano & $5.106,55$ & $\begin{array}{l}\text { Área de Tensão Ecológica com contato entre Savana (S) e Floresta Estacional } \\
\text { (C ou F) e Savana Arborizada com Floresta de Galeria, Água e Pecuária }\end{array}$ & $\mathrm{VI}$ & Baixo \\
\hline
\end{tabular}

${ }^{1}$ Capacidade de uso das terras; ${ }^{2}$ Conflito de uso da terra. 
Do total da área municipal em 2,64\% ocorreu alto conflito de uso (Figura 14), pois deveriam ser destinadas às Áreas de Preservação Permanente - APP, por estarem próximas a corpos d'água e apresentarem solos de alta erodibilidade em relevo acidentado, mas estão sendo utilizados para Pecuária, gerando perturbações no ambiente. A ação antrópica em áreas potencialmente frágeis e com altos níveis de suscetibilidade à erosão, para fins de uso agropecuário, provoca erosão dos solos, assoreamento e poluição dos cursos d'água, tanto pelo uso de incrementos agrícolas (Ex.: agrotóxicos e excesso de fertilizantes) como por dejetos e artigos humanos (Ex.: esgotos e lixo). (SILVA NETO \& NUNES, 2011; KAUANO \& PASSOS, 2008). Em casos como esses, é recomendada a adoção de medidas preservacionistas e/ou a implantação de projetos visando recuperação dessas áreas, minimizando a degradação dos ambientes naturais.

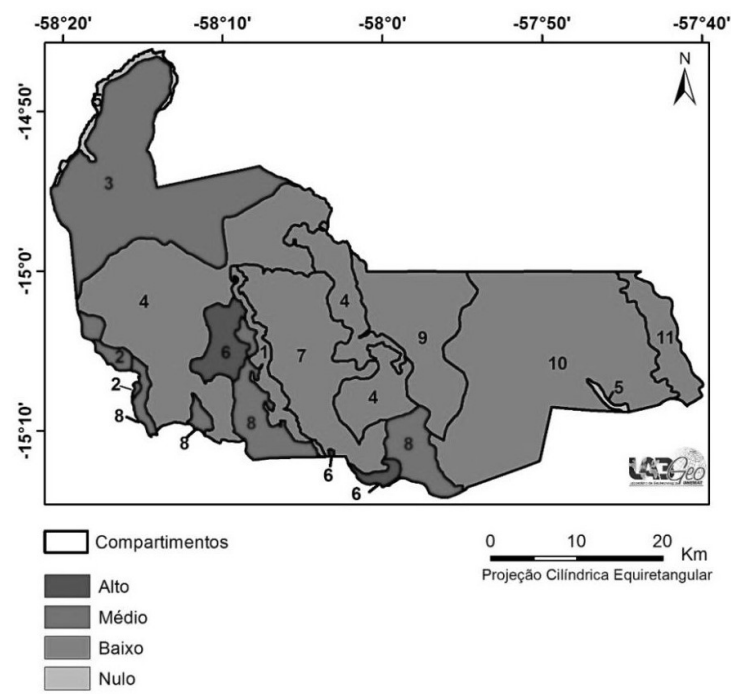

Figura 14. Conflitos de uso da terra no município de Salto do Céu - MT.

No município estudado cerca de $23,74 \%$ da área territorial apresentaram médio conflito de uso (Tabela 3), ocorrido nos compartimentos 2, 3 e 8 devido ao uso da terra para a atividade Pecuária em relevos forte ondulados $(20,1-45 \%)$, sendo que a capacidade de uso indicou que esta é propícia para conservação ou reflorestamento. Conforme Franandes et al. (2008), a cobertura vegetal proporcionada pelo reflorestamento das áreas com menor capacidade de uso beneficia a manutenção e desenvolvimento de espécies nativas da fauna e flora. Propiciando também um aumento na infiltração de água no solo e reduzindo a erosão (BERTOLINI \& LOMBARDI NETO, 1994). Assim, a utilização de áreas com níveis aceitáveis dos fatores limitantes, faz com que fatores climáticos, como a ocorrência de estiagem, sejam minimizados (RAMPIM et al., 2012).

\section{Conclusões}

Concluiu-se que a vegetação natural foi suprimida para que ocorresse a expansão da Pecuária e da área urbana, demostrando que a alteração da paisagem está condicionada pela economia regional, em que a Pecuária constitui a principal atividade.

A análise indicou que o município de Salto do Céu possui terras com alto potencial de uso para Pecuária por apresentarem aptidão para o desenvolvimento da atividade, o que sugere que essas áreas se 
encontram em relativo equilíbrio entre o suporte ecológico (no que diz respeito principalmente à susceptibilidade à erosão linear) e a exploração socioeconômica.

Há necessidade de readequação do uso das terras nas áreas que apresentaram atividades em que ocorre alto conflito, bem como a fiscalização e controle nas mudanças dos usos, para que não ocorram problemas futuros relacionados à erosão.

\section{REFERÊNCIAS}

ABDON, M.. Os impactos ambientais no meio físico- erosão e assoreamento na bacia hidrográfica do Rio Taquari, MS, em decorrência da pecuária. Tese (Doutorado em Ciências da Engenharia Ambiental) - Universidade de São Paulo, São Paulo, 2004.

ALMEIDA, V. P.; ALVES, M. C.; SILVA, E. C.; OLIVEIRA, S. A.. Rotação de culturas e propriedades físicas e químicas em Latossolo Vermelho de Cerrado sob preparo convencional e semeadura direta em adoção. Revista Brasileira de Ciências do Solo, Viçosa, v.32, n.3, p.1227-1237, 2008.

ANTUNES, F.; DIAS, E.; CASTRO, L. D.; BORBA, P.; MACIEL, S. CODECÇO, V.; SAMPAIO, F.. Influência da declividade no solo. Ciência \& Consciência, Brasília, v.31, n.12,1969.

BACHA, C. J. C.. O Sistema Agroindustrial da Madeira no Brasil. Revista Econômica do Nordeste, Fortaleza, v.32, n.4, p.975-993, 2001.

BERTOLINI, D.; LOMBARDI NETO, F.. Manual técnico de manejo e conservação de solo e água: embasamento técnico do Programa Estadual de Microbacias Hidrográficas. Campinas: CATI, 1994. v.1, p.1-15 (CATI. Manual, 38).

BERTOLINI, D.; BELLINAZZI JÚNIOR, R.. Levantamento do meio físico para determinação da capacidade de uso das terras. 2 ed. Campinas,SP: CATI, 1994.

BRASIL. Lei n. 12.651 de 25 de maio de 2012. Institui o Código Florestal. Brasília: DOU, 2012.

CÂMARA, G.; SOUZA, R. C. M.; FREITAS, U. M.; GARRIDO, J. SPRING: Integrating remote sensing and GIS by objectoriented data modeling. Computers \& Graphics, São José dos Campos, v.20, n.3, p.395-403, 1996.

CARVALHO, M. S. B. S.; SOUZA, M. J. N.; FREITAS FILHO, M. R.; SOARES, A. M. L.. Caracterização do uso e ocupação do estuário e entorno do Rio Pirangi (CE). In: SIMPÓSIO BRASILEIRO DE SENSORIAMENTO REMOTO, 11. Anais. Belo Horizonte: INPE, 2003.

COSTA, T. A.; SOARES, V. P.; RIBEIRO, C. A. A. S.; GLERIANI, J. M.. Conflitos de Uso da Terra na Microbacia do São Bartolomeu - Viçosa, MG. Floresta e Ambiente, Seropédica, v.20, n.3, p.281-295, 2013. DOI: http://dx.doi.org/10.4322/floram.2013.023

DUARTE, L. M. G.; THEODORO, S. H.. Dilemas do cerrado: entre o ecologicamente (in) correto e o socialmente (in) justo. Rio de Janeiro: Garamond, 2002.
EMBRAPA. Centro Nacional de Pesquisas de solos. Sistema Brasileiro de Classificação de Solos. 2 ed. Rio de Janeiro: Embrapa-CNPS, 2006.

ESRI. ArcGis advanced: realease 10. 5. Redlands, CA: Environmental Systems Research Institute, 2017.

FARINASSO, M.; CARVALHO JÚNIOR, O. A.; GUIMARÃES, R. F.; GOMES, R. A. T.; RAMOS, V. M.. Avaliação qualitativa do potencial de erosão laminar em grandes áreas por meio da Eups - Equação Universal de perdas de solos utilizando novas metodologias em SIG para os cálculos dos seus fatores na região do Alto Parnaíba - PI-MA. Revista Brasileira de Geomorfologia, v.7, n.2, p.73-85, 2006.

FERNANDES, P. A.; PESSÔA, V. L. S.. O Cerrado e Suas Atividades Impactantes: Uma Leitura Sobre o Garimpo, a Mineração e a Agricultura Mecanizada. OBSERVATORIUM: Revista Eletrônica de Geografia, v.3, n.7, p.19-37, 2011.

FRANANDES, L. A.; LOPES, P. S. N.; D`ANGELO, S.; DAYRELL, C. A.; SAMPAIO, R. A.. Relação entre o conhecimento local, atributos químicos e físicos do solo e uso das terras. Revista Brasileira de Ciências do Solo, Viçosa, v.32, n.3, p.13551365,2008

FREITAS, L. E.; SILVA, C. C.; NEVES, S. M. A. S.; NEVES, R. J.; NUNES, M. C. M.. Analysis on the susceptibility to erosion and land use conflicts by geotechnologies in the microregion Jauru - Mato Grosso State, Brazil. Geografia, Rio Claro, v.40, p.99-118, 2015.

HERMUCHE, P. M.; GUIMARÃES, G. M. A.; CASTRO, S. S.. Análise dos compartimentos morfopedológicos como subsídio ao planejamento do uso do solo em Jataí - GO. GEOUSP - Espaço e Tempo, São Paulo, v.1, n.26, p113-131, 2009.

IBGE. Instituto Brasileiro de Geografia e Estatística. Censo Demográfico - 2010. Rio de Janeiro: IBGE, 2010.

IBGE. Instituto Brasileiro de Geografia e Estatística. Manual técnico da vegetação brasileira. $3 \mathrm{ed}$. Rio de Janeiro: IBGE, 2012.

KAUANO, E. E.; PASSOS, E.. Análise do uso da terra em áreas de preservação permanente da bacia hidrográfica do Rio da Gama, Tijucas do Sul, Paraná. Rev. Acad., Ciênc. Agrár. Ambient., Curitiba, v.6, n.2, p.181-190, 2008.

LEPSCH, I. F.; BELLINAZZI JR., R.; BERTOLINI, D.; ESPÍNDOLA, C. R.. Manual para levantamento utilitário do meio físico e classificação de terras no sistema de capacidade de uso. 4 ed. Campinas: SBCS, 1991. 
LIMA, J. A. S.; MENNEGUELLI, N. A.; GAZEL FILHO, A. B.; PÉREZ, D. V.. Agrupamento de espécies arbóreas de uma floresta tropical. Pesq. Agropec. Bras., Brasília, v.38, n.1, p.109-116, 2003.

MATO GROSSO (Estado). Secretaria de Estado e Planejamento e Coordenação Geral. Anuário Estatístico de Mato Grosso. Cuiabá: SEPLAN, 2013.

MATO GROSSO (Estado). Secretaria de Estado de Planejamento e Coordenação Geral. MOREIRA, M. L. C.; VASCONCELOS, T. N. N. (Orgs). Mato Grosso: solos e paisagem. Cuiabá: SEPLAN, 2007.

MATO GROSSO. Lei no 4.152 de 13 de dezembro de 1979. Institui a criação do município de Salto do Céu. Mato Grosso: 13 Dez 1979.

MYERS, N.; MITTERMEIER, R. A.; MITTERMEIER, C. G.; FONSECA, G. A. B.; KENT, J.. Biodiversity hotspots for conservation priorities. Nature, v.403, p.853-858, 2000.

MIRANDA, M. R. S.; DASSOLLER, T. F.; NEVES, S. M. A. S.; NEVES, R. J.; CAIONI, C.; SILVA, L. B. Dinâmica do Uso da Terra no Assentamento Facão, Cáceres/MT: Subsídios para à Conservação do Cerrado. Cadernos de Agroecologia, Porto Alegre, v.9, n.4, p.1-9, 2014.

MIRANDA, M. R. S.; NEVES, L. F.; KREITLOW, J. P.; NEVES, S. M. A. S.; NEVES, R. J.. Queimadas

no município matogrossense de Cáceres e as mudanças na cobertura vegetal e uso da terra. In: Simpósio de Geotecnologias no Pantanal, 5. Anais. Campo Grande: INPE, 2014.

MONNIGEL, A. R.; PORTO, S. M. A.; ALVES, M. C.; VALÉRIO FILHO, W. V.. Propriedades químicas de um latossolo roxo de cerrado cultivado com algodão sob diferentes preparos e adubações. Revista em Agronegócios em Meio Ambiente, v.2, n.1, p.41-54, 2009.

NUNES, M. C. M.; NEVES, S. M. A. S.; NEVES, R. J.; KREITLOW, J. P.; CHIMELLO, A. M.. Susceptibility to Water Erosion of Soils From the Municipality Salto do Céu, SW Mato Grosso State, Brazil - Brazil. Revista Geografia, Rio Claro, v.38, número especial, p.191-20, 2013.

PAULINO, V. T.; TEIXEIRA, E. M. L.. Sustentabilidade de pastagens: manejo adequado como medida redutora da emissão de gases de efeito estufa. 2016.

PESSOA, S. P. M.; GALVANIN, E. A. S.; KREITLOW, J. P.; NEVES, S. M. A. S.; NUNES, J. R. S.; ZAGO, B. W.. Análise espaço-temporal da cobertura vegetal e uso da terra na interbacia do rio Paraguai médio MT, Brasil. Revista Árvore, v.37, n.1, p.119-128, 2013.

RAMPIM, L.; TAVARES FILHO, J.; BEHLAU, F.; ROMANO, D.. Determinação da capacidade de uso do solo visando o manejo sustentável para uma média propriedade em Londrina-PR. Biosci. J., Uberlândia, v.28, n.2, p.251-264, 2012.

RÉUS, M. S.. Análise do Conflito do Uso de Solo como Ferramenta para o Planejamento Ambiental Empregando Técnicas de Geoprocessamento: estudo de Caso: Lagoa do
Faxinal, Içara, SC. Monografia (Graduação em Engenharia Ambiental e Sanitária) - Universidade do Extremo Sul Catarinense, Criciúma, 2010.

RIBEIRO, J. C.; SALOMÃO, F. X. T.. Abordagem Morfopedológica Aplicada ao Diagnóstico e Prevenção de Processos Erosivos na Bacia Hidrográfica do Alto Rio da Casca, MT. Geociências, São Paulo, v.22, n.1, p.83-95, 2003.

SABOGAL, C.; ALMEIDA, E.; MARMILLOD, D.; CARVALHO, J. O. P.. Silvicultura na Amazônia brasileira: avaliação de experiências e recomendações para implementação e melhoria dos sistemas. Amazonas: CIFOR, 2006.

SALO, J.; RÄSÄNEM, M.. Hierarchy of landscape patterns in western Amazon. In: HOLM-NIELSEN, L. F.; NIELSEN, I. C.; BALSLEV, H.. Tropical forests: botanical dynamics, speciation and diversity. London: Academic Press, 1990. p.35-45.

SALOMÃO, F. X. T.. Controle e Prevenção dos Processos Erosivos. In: GUERRA, A. J. T.; SILVA, A. S.; BOTELHO, R. G.M.. Erosão e Conservação dos Solos: Conceitos, Temas e Aplicações. 6 ed. Rio de Janeiro: Bertrand Brasil, 1999. p.231-243.

SANTOS, A. B; PETRONZIO, J. A. C.. Mapeamento de uso e ocupação do solo do município de Uberlândia-MG utilizando técnicas de Geoprocessamento. In: Simpósio Brasileiro de Sensoriamento Remoto, 5. Anais. Curitiba: INPE, 2011.

SCHIAVO, B. N. V.; TERRA, L. G.; DUARTE, M. M.; GATIBONI, T. N.. Uso de imagens orbitais multitemporais para caracterização de uso e ocupação da terra no município de São Borja. Revista Eletrônica em Gestão, Educação e Tecnologia Ambiental Santa Maria, Santa Maria, v.19, n.2, p.1526-1534, 2015. DOI: http://doi.org/10.5902/2236117015532

SCHNEIDER, S.; TARTARUGA, I. G. P.. Território e abordagem territorial: das referências cognitivas aos aportes aplicados à análise dos processos sociais rurais. Raízes, Campina Grande, v.23, n.01 e 02, p.99-116, 2004.

SILVA NETO, J. C. A.; NUNES, J. O. R.. Potencial à erosão laminar utilizando Sistema de Informações Geográficas: aplicações na bacia hidrográfica do Rio Salobra-MS. In: SIMPÓSIO BRASILEIRO DE SENSORIAMENTO REMOTO, 15. Anais. Curitiba: INPE, 2011.

SEABRA, V. S.; CRUZ, C. M.. Mapeamento da Dinâmica da Cobertura e Uso da Terra na Bacia Hidrográfica do Rio São João, RJ. Sociedade \& Natureza, Uberlândia, v.25, n.2, p.411-426, 2013.

SPÖRL, C. Análise da fragilidade ambiental relevo-solo com aplicação de três modelos alternativos nas altas bacias do rio Jaguarimirim, Ribeirão do quartel e Ribeirão da Prata. Dissertação (Mestrado em Geografia Física) Universidade de São Paulo, São Paulo, 2001.

TARIFA, J. R.. Mato Grosso: clima: análise e representação cartográfica. Cuiabá: Entrelinhas, 2011.

THOMAZ, E. L.. Dinâmica do uso da terra e degradação do solo na bacia do rio Guabiroba - Guarapuava/PR. Revista RA'E GA, Curitiba, v.13, n.1, p.109-128, 2007. DOI: http://dx.doi.org/10.5380/raega.v13i0.3439. 
TORRES, R. B.; MARTINS, F. R.; KINOSHITA, L. S.. Climate, soil and tree flora relationships in forest in the state of São Paulo, southeastern Brazil. Rev. Bras. Bot., São Paulo, v.20, n.1, p.41-49, 1997.
ZUO, X.; ZHAO, H.; ZHAO, X.; ZHANG, T.; GUO, Y.; WANG, S.; DRAKE, S.. Spatial patternand heterogeneity of soil properties in sand dunes under grazing and restoration in Horquin Sandy Land, Northern China. Soil \& Tillage Research, Amsterdam, v.99, n.2, p.202-212, 2008. 